\title{
Suplementação de glicina para pintos de corte submetidos a dietas com diferentes relações treonina:lisina digestíveis
}

\author{
Glycine supplementation to broiler chicks subjected to diets with different digestible \\ threonine: digestible lysine relations
}

\author{
BERNARDINO, Verônica Maria Pereira ${ }^{1 *}$; ALBINO, Luiz Fernando Teixeira ${ }^{1}$; \\ ROSTAGNO, Horácio Santiago ${ }^{1}$; MENDES, Fabrícia Queiroz ${ }^{1}$; PEREIRA, Cinthia \\ Maria Carlos ${ }^{1}$; MAIA, Rosana Cardoso ${ }^{1}$; NARDELLI, Nicole Batelli de Souza ${ }^{2}$, \\ RETES, Pâmela Lacombe ${ }^{2}$
}

\author{
${ }^{1}$ Universidade Federal de Viçosa, Centro de Ciências Agrárias, Departamento de Zootecnia, Viçosa, \\ Minas Gerais, Brasil. \\ ${ }^{2}$ Universidade Federal de Lavras, Centro de Ciências Agrárias, Departamento de Zootecnia, Lavras, \\ Minas Gerais, Brasil. \\ *Endereço para correspondência: veronicampb@gmail.com
}

\section{RESUMO}

O experimento foi conduzido com o objetivo de avaliar a influência que diferentes relações treonina:lisina digestíveis e suplementação ou não de glicina exercem sobre o desempenho de frangos de corte na fase inicial. Foram utilizados 560 pintos de corte, machos, da linhagem Cobb, distribuídos em delineamento inteiramente casualisado, em arranjo fatorial $3 \times 2+1$, sendo três relações de treonina:lisina digestíveis $(55 ; 65$ e $75 \%$ ), suplementados ou não com glicina mais um adicional, que continha proteína de origem animal, com relação treonina:lisina digestíveis de $65 \%$. Utilizaram-se oito repetições e 10 aves por unidade experimental. $\mathrm{O}$ consumo de ração, o ganho de peso e a conversão alimentar não foram influenciados pelos níveis de treonina. A suplementação de glicina reduziu o consumo de ração, aumentou o ganho de peso e melhorou a conversão alimentar das aves. Não houve interação entre os níveis de treonina e a suplementação de glicina sobre o desempenho das aves. A suplementação de glicina foi essencial para melhorar o desempenho de pintos de corte. Conclui-se que a relação de $55 \%$ de treonina digestível: lisina digestível $(0,631 \%$ de treonina digestível), suplementada com glicina é suficiente para atender as exigências de pintos de corte de 8 a 21 dias de idade.

Palavras-chave: aminoácidos essenciais, consumo de ração, conversão alimentar, ganho de peso

\section{SUMMARY}

The experiment was conducted with the objective evaluating the different digestible threonine: digestible lysine ratio and supplementation or not of glycine on the performance of broilers in the period from eight to 21 days of age. Five hundred and sixty male broiler chicks of the Cobb strain were used, distributed in a completely randomized design, in a factorial arrangement of $3 \times 2+1$, with three digestible threonine:lysine ratio $(55,65$ and $75 \%$ ), supplemented or not with glycine plus an additional treatment, containing animal protein, with digestible threonine:lysine ratio of $65 \%$. Eight replicates were used per treatment and 10 birds were used per experimental unit. The feed intake, the weight gain and the feed conversion were not influenced by the levels of threonine. The supplementation of glycine reduced the feed intake, increased the weight gain and improved the feed conversion of the birds. There was no interaction between the levels of threonine and the supplementation of glycine on the broilers performance. The supplementation of glycine was essential to improve the broiler chicks performance. The digestible threonine: lysine ratio of $55 \% \quad(0.631 \%$ of digestible threonine $)$, supplemented with glycine is sufficient to meet the requirements of broiler chicks from 8 to 21 days of age.

Keywords: essential amino acids, feed conversion, feed intake, weight gain 


\section{INTRODUÇ̃̃̃O}

A proteína é um nutriente de importância fundamental para a deposição de tecido muscular em frangos de corte. Para que esta deposição seja eficiente, tanto a quantidade quanto a qualidade da proteína da dieta devem ser adequadas.

Durante muito tempo as dietas para aves foram formuladas com base no conceito de proteína bruta, o que poderia resultar em rações com conteúdo de aminoácidos superior aos requerimentos reais dos animais. Segundo Costa et al. (2001) o excesso de aminoácido é catabolizado na forma de ácido úrico, no qual ocorre gasto de energia, o que pode afetar a deposição de tecidos musculares. Para se obter ótimo desempenho com nível proteico menor é necessário atender as exigências em aminoácidos essenciais sem, entretanto, oferecê-los em excesso.

A treonina é o terceiro aminoácido limitante para frangos de corte em dietas à base de milho e de farelo de soja, e de importancia para a melhor utilização da lisina. Rostagno et al. (2005) recomendam a relação $65,0 \%$ treonina:lisina digestível e $1,9 \%$ de glicina total para frangos de corte na fase inicial, pois as exigências de glicina e de serina é maior nesta fase.

$\mathrm{O}$ aminoácido glicina participa da composição da molécula de ácido úrico e é considerado aminoácido essencial para pintos de corte. A treonina pode ser hidrolisada formando glicina, e assim pode atender a exigência deste aminoácido (KIDD \& KERR, 1996). Desta forma, a glicina e a serina podem se tornar deficientes para os pintos de corte, quando alimentados com dietas vegetais com baixo nível de proteína bruta e com níveis inferiores de treonina (CORZO et al., 2004). Em rações que contêm produtos de origem animal, principalmente farinha de carne e ossos, muitas vezes não é necessária a adição de glicina mais serina sintéticas, uma vez que os níveis destes aminoácidos presentes nestes alimentos são suficientes para atender a necessidade das aves.

Diante do exposto, objetivou-se com este trabalho avaliar dietas vegetais com diferentes relações treonina digestível: lisina digestível, suplementadas ou não com glicina sobre o desempenho de pintos de corte no período de 8 a 21 dias de idade.

\section{MATERIAL E MÉTODOS}

O trabalho foi desenvolvido no setor de Avicultura do Departamento de Zootecnia da Universidade Federal de Viçosa. Foram utilizados 560 pintos de corte, machos, da linhagem Cobb 500, distribuídos em delineamento inteiramente casualizado, num arranjo fatorial $3 \times 2+1$, sendo três relações treonina digestível: lisina digestível $(55,0 \% ; 65,0 \% ; 75,0 \%)$, suplementadas ou não com $0,4 \%$ de glicina (Tabela 1 ) e um tratamento adicional que continha proteína de origem animal, com relação treonina digestível: lisina digestível em $65 \%$, sendo a fonte desta proteína a farinha de carne e ossos. Foram sete tratamentos, oito repetições e dez aves por unidade experimental, em um total de 56 unidades experimentais.

As aves no período pré-inicial (um a sete dias) foram criadas em galpão de alvenaria, receberam ração basal de acordo com as exigências de Rostagno et al. (2005), e foram mantidas sob luz artificial durante 24 horas por dia.

As dietas foram formuladas para atenderem as exigências preconizadas por Rostagno et al. (2005), exceto para treonina e glicina (Tabela 2). As demais 
Rev. Bras. Saúde Prod. Anim., Salvador, v.13, n.1, p.173-180 jan/mar, 2012 http://www.rbspa.ufba.br ISSN 15199940

dietas experimentais foram obtidas por meio da suplementação de L-treonina $(98,0 \%)$ e de glicina em substituição ao amido. As aves receberam água e ração ad libitum.

As análises aminoacídicas das dietas foram realizadas pelo Laboratório da Ajinomoto Animal Nutrition.

As aves e a ração foram pesadas no início e no final do período experimental (aos oito e 21 dias de idade), para obtenção do ganho de peso, do consumo de ração e da conversão alimentar. A mortalidade das aves foi registrada e considerada para a correção dos dados de desempenho. Calculou-se o consumo de treonina e de glicina + serina para melhor compreender os resultados de desempenho.

Tabela 1. Composição percentual das dietas experimentais

\begin{tabular}{|c|c|c|c|c|c|c|c|}
\hline \multirow{2}{*}{$\begin{array}{l}\text { Ingredientes } \\
\text { Milho }\end{array}$} & \multicolumn{2}{|c|}{$55 \%$} & \multicolumn{2}{|c|}{$65 \%$} & \multicolumn{2}{|c|}{$75 \%$} & \multirow{2}{*}{$\begin{array}{c}65 \% \\
31,946\end{array}$} \\
\hline & 33,477 & 33,477 & 33,477 & 33,477 & 33,477 & 33,477 & \\
\hline Sorgo Baixo Tanino & 30,000 & 30,000 & 30,000 & 30,000 & 30,000 & 30,000 & 30,000 \\
\hline Farelo de soja 45\%) & 29,397 & 29,397 & 29,397 & 29,397 & 29,397 & 29,397 & 28,740 \\
\hline $\begin{array}{l}\text { Farinha de Carne e } \\
\text { Ossos }(42 \%)\end{array}$ & - & - & - & - & - & - & 5,000 \\
\hline Óleo de soja & 2,198 & 2,198 & 2,198 & 2,198 & 2,198 & 2,198 & 2,166 \\
\hline Fosfato bicálcico & 1,811 & 1,811 & 1,811 & 1,811 & 1,811 & 1,811 & 0,000 \\
\hline Calcário & 0,913 & 0,913 & 0,913 & 0,913 & 0,913 & 0,913 & 0,762 \\
\hline Sal comum & 0,492 & 0,492 & 0,492 & 0,492 & 0,492 & 0,492 & 0,429 \\
\hline L Lisina-HCl (97\%) & 0,350 & 0,350 & 0,350 & 0,350 & 0,350 & 0,350 & 0,270 \\
\hline DL Metionina (98\%) & 0,300 & 0,300 & 0,300 & 0,300 & 0,300 & 0,300 & 0,284 \\
\hline L Arginina $(98,5 \%)$ & 0,048 & 0,048 & 0,048 & 0,048 & 0,048 & 0,048 & ------- \\
\hline L Valina (99\%) & 0,049 & 0,049 & 0,049 & 0,049 & 0,049 & 0,049 & ------ \\
\hline L Treonina (98\%) & ---- & ---- & 0,116 & 0,116 & 0,233 & 0,233 & 0,087 \\
\hline Amido & 0,650 & 0,250 & 0,534 & 0,134 & 0,417 & 0,017 & ---- \\
\hline Glicina & ------- & 0,400 & ------- & 0,400 & ------- & 0,400 & ----- \\
\hline Cloreto de Colina $(60 \%)$ & 0,100 & 0,100 & 0,100 & 0,100 & 0,100 & 0,100 & 0,100 \\
\hline Suplemento vitamínico ${ }^{1}$ & 0,100 & 0,100 & 0,100 & 0,100 & 0,100 & 0,100 & 0,100 \\
\hline Suplemento mineral ${ }^{2}$ & 0,050 & 0,050 & 0,050 & 0,050 & 0,050 & 0,050 & 0,050 \\
\hline Anticoccidiano $^{3}$ & 0,055 & 0,055 & 0,055 & 0,055 & 0,055 & 0,055 & 0,055 \\
\hline Antioxidante $^{4}$ & 0,010 & 0,010 & 0,010 & 0,010 & 0,010 & 0,010 & 0,010 \\
\hline
\end{tabular}

${ }^{1}$ Suplemento mineral - Níveis de garantia por quilo de ração: Manganês 80,0mg ; Ferro - 50,0mg; Zinco 50,0mg; Cobre - 10,0mg ; Cobalto - 1,0mg ; Iodo - 1,0mg.

${ }^{2}$ Suplemento vitamínico -Níveis de garantia por quilo de ração: vitamina A - 10.000 UI; vitamina D3 2.000 UI; Vitamina E - 30 UI; Vitamina B1 - 2,0mg ; vitamina B6 - 4,0mg; Ac Pantotênico - 12,0mg; Biotina - 0,10mg; Vitamina K3 - 3,0mg ; Ácido fólico - 1,0mg ; Ácido nicotínico- 50,0mg ; Vitamina B12 - $15 \mu \mathrm{g}$; Selênio - 0, 25mg.

${ }^{3}$ Coxistac (Salinomicina 12\%).

${ }^{4}$ Hidroxi butil tolueno (antioxidante). 
Tabela 2. Valores calculados e analisados de aminoácidos e proteína bruta das dietas experimentais, expressos em \%

\begin{tabular}{|c|c|c|c|c|c|c|c|}
\hline \multirow[b]{2}{*}{ Nutrientes } & \multicolumn{2}{|c|}{$55 \%$} & \multicolumn{2}{|c|}{$65 \%$} & \multicolumn{2}{|c|}{$75 \%$} & \multirow[b]{2}{*}{$65 \%$} \\
\hline & $\begin{array}{c}\text { Sem } \\
\text { Glicina }\end{array}$ & $\begin{array}{c}\text { Com } \\
\text { Glicina }\end{array}$ & $\begin{array}{c}\text { Sem } \\
\text { Glicina }\end{array}$ & $\begin{array}{c}\text { Com } \\
\text { Glicina }\end{array}$ & $\begin{array}{c}\text { Sem } \\
\text { Glicina }\end{array}$ & $\begin{array}{c}\text { Com } \\
\text { Glicina }\end{array}$ & \\
\hline & \multicolumn{7}{|c|}{ Valores Calculados } \\
\hline Proteína bruta $(\%)$ & 19,158 & 19,158 & 19,158 & 19,158 & 19,158 & 19,158 & 20,652 \\
\hline Energia metabolizável (kcal/kg) & 3.000 & 3.000 & 3.000 & 3.000 & 3.000 & 3.000 & 3.000 \\
\hline Cálcio (\%) & 0,884 & 0,884 & 0,884 & 0,884 & 0,884 & 0,884 & 0,884 \\
\hline Fósforo disponível (\%) & 0,442 & 0,442 & 0,442 & 0,442 & 0,442 & 0,442 & 0,444 \\
\hline Arginina digestível (\%) & 1,203 & 1,203 & 1,203 & 1,203 & 1,203 & 1,203 & 1,397 \\
\hline Metionina+Cistina digestível (\%) & 0,814 & 0,814 & 0,814 & 0,814 & 0,814 & 0,814 & 0,814 \\
\hline Valina digestível (\%) & 0,860 & 0,860 & 0,860 & 0,860 & 0,860 & 0,860 & 0,860 \\
\hline Lisina digestível (\%) & 1,146 & 1,146 & 1,146 & 1,146 & 1,146 & 1,146 & 1,146 \\
\hline Treonina digestível (\%) & 0,631 & 0,631 & 0,745 & 0,745 & 0,860 & 0,860 & 0,745 \\
\hline \multirow[t]{2}{*}{ Glicina + Serina $(\%)$} & 1,698 & 2,100 & 1,698 & 2,100 & 1,698 & 2,100 & 2,081 \\
\hline & \multicolumn{7}{|c|}{ Valores analisados } \\
\hline Proteína bruta & 20,20 & 20,70 & 19,88 & 20,98 & 21,16 & 21,22 & 22,56 \\
\hline Metionina + Cistina & 0,867 & 0,896 & 0,880 & 0,863 & 0,905 & 0,793 & 0,871 \\
\hline Lisina & 1,200 & 1,130 & 1,143 & 1,162 & 1,363 & 1,259 & 1,328 \\
\hline Arginina & 1,173 & 1,096 & 1,324 & 1,020 & 1,359 & 1,317 & 1,416 \\
\hline Treonina & 0,701 & 0,660 & 0,762 & 0,750 & 0,998 & 0,917 & 0,882 \\
\hline Glicina & 0,750 & 1,061 & 0,749 & 1,107 & 0,826 & 1,171 & 1,112 \\
\hline Serina & 0,939 & 0,921 & 0,956 & 0,917 & 1,062 & 0,970 & 1,060 \\
\hline
\end{tabular}


Rev. Bras. Saúde Prod. Anim., Salvador, v.13, n.1, p.173-180 jan/mar, 2012 http://www.rbspa.ufba.br ISSN 15199940

As análises estatísticas das variáveis de desempenho foram realizadas pelo programa estatístico SAEG (UFV, 2000). Os resultados obtidos foram submetidos à análise de variância. As médias das diferentes relações treonina digestível: lisina digestível foram comparadas pelo teste de Student-Newman-keul's, ao nível de $5,0 \%$ de probabilidade. Adicionalmente, as médias dos tratamentos com diferentes relações treonina digesível: lisina digestível, suplementados ou não com glicina foram comparadas ao tratamento controle por meio da análise do contraste.

\section{RESULTADOS E DISCUSSÃO}

Não se observou efeito das diferentes relações treonina digestível: lisina digestível ou presença de glicina na dieta sobre a mortalidade das aves $(\mathrm{p}>0,05)$ no período de oito a 21 dias de idade, a viabilidade média foi de $98,0 \%$. Não houve interação $(\mathrm{p}>0,05)$ entre as diferentes relações treonina: lisina digestíveis e suplementação ou não de glicina para consumo de ração, ganho de peso e conversão alimentar (Tabela 3), o que corrobora os resultados verificados por Dionízio (2003).

Tabela 3. Efeitos da relação treonina: lisina digestível sobre o desempenho de pintos de corte no período de oito a 21 dias de idade

\begin{tabular}{|c|c|c|c|c|c|c|c|c|c|}
\hline \multirow{3}{*}{$\begin{array}{l}\text { Relação } \\
\text { Tre:Lis (\%) }\end{array}$} & \multirow{2}{*}{\multicolumn{2}{|c|}{$\begin{array}{c}\text { Consumo de ração } \\
(\mathrm{g})\end{array}$}} & \multirow{3}{*}{ Média } & \multirow{2}{*}{\multicolumn{2}{|c|}{$\begin{array}{c}\text { Ganho de peso } \\
(\mathrm{g})\end{array}$}} & \multirow{3}{*}{ Média } & $\begin{array}{r}\text { Conv } \\
\text { alimen }\end{array}$ & $\begin{array}{l}\text { rsão } \\
(\mathrm{g} / \mathrm{g})\end{array}$ & \multirow{3}{*}{ Média } \\
\hline & & & & & & & \multicolumn{2}{|c|}{ Glicina } & \\
\hline & Sem & Com & & Sem & Com & & Sem & Com & \\
\hline 55 & 1001,10 & 980,67 & 990,89 & 726,00 & 772,00 & 749,00 & $1,379 *$ & 1,271 & 1,325 \\
\hline 65 & 1024,51 & 992,78 & 1008,64 & 764,00 & 771,00 & 767,50 & $1,345^{*}$ & 1,289 & 1,317 \\
\hline 75 & 992,91 & 977,31 & 985,11 & 745,00 & 758,00 & 751,50 & $1,336^{*}$ & 1,290 & 1,313 \\
\hline Média & $1006,20^{\mathrm{A}}$ & $983,60^{\mathrm{B}}$ & & $745,0^{\mathrm{B}}$ & $767,0^{\mathrm{A}}$ & & $1,353^{\mathrm{B}}$ & $1,283^{\mathrm{A}}$ & \\
\hline FCO & \multicolumn{2}{|c|}{959,35} & & \multicolumn{2}{|c|}{774,00} & \multicolumn{4}{|c|}{1,240} \\
\hline $\mathrm{CV}(\%)$ & \multicolumn{2}{|c|}{$3,70 \%$} & & \multicolumn{2}{|c|}{$4,95 \%$} & \multicolumn{4}{|c|}{$3,74 \%$} \\
\hline
\end{tabular}

O consumo de ração não diferiu entre $(p>0,05)$ as diferentes relações treonina digestível: lisina digestível testadas e o tratamento controle. (Tabela 3). A variação na concentração de treonina dos diferentes tratamentos não interferiu no consumo das aves. Por este resultado pode-se inferir que o provável imbalanço causado pelas diferentes relações treonina: lisina digestíveis não foi suficiente para afetar o consumo de ração, e também foi verificado resultado semelhante a este por Dionízio (2003). Porém, Dozier et al. (2003) ao suplementar a dieta basal de pintos de corte com $0,7 \%, 0,14 \%$ e $0,21 \%$ de LTreonina, verificou que o consumo de ração das aves aumentou com a elevação do nível de treonina da dieta $(\mathrm{p}<0,001)$.

Já para o aminoácido L-Glicina, ao ser suplementado na ração, houve redução 
significativa no consumo desta $(\mathrm{p}<0,05)$, o que difere dos resultados encontrados por Dionízio (2003), que suplementou $0,104 \%$ e $0,222 \%$ de glicina na dieta de frangos de corte de 22 a 42 dias de idade e não observou diferença no consumo de ração. Provavelmente a glicina estava deficiente nas rações em que este aminoácido não foi suplementado, o que tornou necessário maior consumo de ração pelas aves a fim de suprir esta deficiência. Assim, a suplementação de L-Glicina nas rações permitiu atender as necessidades deste aminoácido pelas aves com menor consumo.

O ganho de peso das aves alimentadas com diferentes relações treonina digestível: lisina digestível não diferiu $(\mathrm{p}>0,05)$ do ganho de peso das aves alimentadas com dietas que continham farinha de carne e ossos. Entretanto, a suplementação com L-Glicina aumentou o ganho de peso (Tabela 3), o que evidencia que as dietas sem a suplementação de glicina não atendiam as necessidades nutricionais deste aminoácido. $\mathrm{O}$ menor ganho de peso das aves alimentadas com rações sem suplementação de L-Glicina pode ser justificado pela deficiência de glicina + serina na ração.

A conversão alimentar foi melhor nas aves alimentadas com as dietas suplementadas com glicina $(\mathrm{P}<0,05)$, o resultado foi consequência do menor consumo de ração e maior ganho de peso destas aves. As aves que consumiram rações com diferentes relações treonina digestível: lisina digestível sem a suplementação de glicina apresentaram maior conversão alimentar $(p<0,05)$ em relação às aves que consumiram farinha de carne e ossos, diferença que não foi observada para as aves alimentadas com suplementação de glicina ( $>>0,05)$. Este resultado pode indicar que, para essas relações, é necessária a suplementação de glicina para obter resultados semelhantes ao tratamento controle, visto que a farinha de carne e ossos atende a necessidade de glicina das aves. Resultados semelhantes foram obtidos por Corzo et al. (2004), Jiang et al. (2005) e Vasconcellos et al. (2011) que observaram melhora na conversão alimentar com o aumento dos níveis de glicina na dieta.

Segundo Corzo et al. (2004), dietas com baixo nível de proteína bruta devem ser suplementadas com aminoácidos essenciais para atender às limitações que possam surgir, em relação às necessidades de aminoácidos. Contudo, Waldroup et al. (2005) demonstraram que a suplementação de $0,2 \%$ de glicina na dieta com baixo nível de proteína bruta para pintos de corte no período de 1 a 21 dias de idade não afetou a conversão alimentar, porém, a suplementação de $0,4 \%$ de glicina melhorou a conversão alimentar. Isto demonstra a essencialidade da glicina para aves na fase inicial, provavelmente devido à baixa eficiência das aves em obter a glicina a partir da quebra da treonina, ou seja, a atividade das enzimas treonina aldolase e treonina desidrogenase, pode não ser metabolicamente eficaz para suprir a necessidade deste aminoácido.

As relações de treonina: lisina digestíveis não proporcionaram diferença significativa na conversão alimentar (Tabela 3), estando de acordo com os resultados obtidos por Waldroup et al. (2005), que não observaram melhora significativa na conversão alimentar com a suplementação de treonina e nem interação da suplementação de treonina e de glicina. Contudo, Dozier et al. (2003) observaram que ao suplementar treonina à dieta basal de pintos de corte, a conversão alimentar das aves foi melhorada $(\mathrm{P}<0,001)$. 
Rev. Bras. Saúde Prod. Anim., Salvador, v.13, n.1, p.173-180 jan/mar, 2012 http://www.rbspa.ufba.br ISSN 15199940

Embora o consumo de ração não tenha sido afetado pelas diferentes relações treonina:lisina digestíveis, o aumento da relação promoveu o aumento na concentração de treonina na ração, o que incidiu no aumento do consumo de treonina $(p<0,05) \quad($ Tabela 4$)$. Este aumento no consumo de treonina também foi observado por Ayasan et al. (2009), quando avaliaram níveis crescentes $(0,70 ; 0,75 ; 0,80 ; 0,85 \mathrm{e}$ $0,90 \%$ ) de treonina nas rações de frangos de corte de 22 a 42 dias de idade. Quando analisada a suplementação de glicina foi observada diminuição no consumo de treonina $(\mathrm{p}<0,05)$, provavelmente devido à redução no consumo de ração por estas aves (Tabela 4). Não houve interação entre as diferentes relações treonina: lisina e a suplementação ou não de glicina $(p<0,05)$ para o consumo de treonina.

Tabela 4. Efeitos da relação treonina:lisina digestível sobre o consumo de treonina (g) e de glicina + serina e pintos de corte no período de oito a 21 dias de idade

\begin{tabular}{|c|c|c|c|c|c|c|c|}
\hline & \multicolumn{4}{|c|}{ Relação Tre:Lis (\%) } & \multirow{2}{*}{$\mathrm{FCO}^{1}$} & \multirow{2}{*}{$\begin{array}{l}\text { CV } \\
(\%)\end{array}$} \\
\hline & & 55 & 65 & 75 & Média & & \\
\hline \multirow{3}{*}{$\begin{array}{l}\text { Consumo de } \\
\text { treonina }(\mathrm{g})\end{array}$} & Sem glicina & $6,317 *$ & $7,633^{*}$ & $8,541 *$ & $7,497^{\mathrm{A}}$ & & \\
\hline & Com glicina & $6,189 *$ & 7,398 & 8,408 & $7,332^{\mathrm{B}}$ & $7,418^{*}$ & 3,79 \\
\hline & Média & 6,253 & $7,516^{\mathrm{b}}$ & $8,475^{\mathrm{a}}$ & & & \\
\hline \multirow{3}{*}{$\begin{array}{l}\text { Consumo de } \\
\text { Glicina+serina } \\
\text { (g) }\end{array}$} & Sem glicina & $16,999 *$ & $17,396^{*}$ & $16,863^{*}$ & $17,086^{\mathrm{B}}$ & & \\
\hline & Com glicina & 20,598 & 20,853 & 20,530 & $20,660^{\mathrm{A}}$ & $19,967^{*}$ & 3,80 \\
\hline & Média & 18,799 & 19,125 & 18,697 & & & \\
\hline
\end{tabular}

${ }^{1}$ Farinha de carne e ossos.

${ }^{\mathrm{AB}}$ Médias seguidas por letras maiúsculas diferentes na mesma coluna são diferentes pelo teste $\mathrm{SNK}(\mathrm{P}<0,05)$.

${ }^{\mathrm{ab}}$ Médias seguidas por letras minúsculas diferentes na mesma linha são diferentes pelo teste $\mathrm{SNK}(\mathrm{P}<0,05)$.

$\mathrm{CV}=$ coeficiente de variação.

Contraste versus o tratamento com FCO significativo $(\mathrm{P}<0,05)$.

As diferentes relações treonina: lisina digestíveis não proporcionaram diferença no consumo de glicina mais serina $(\mathrm{p}>0,05)$. No entanto, as aves alimentadas com dietas suplementadas com glicina tiveram maior consumo $(p<0,05)$ de glicina + serina. As aves submetidas à dieta sem suplementação de glicina consumiram menos $(\mathrm{p}<0,05)$ glicina+serina que as aves alimentadas com dietas que continham farinha de carne e ossos.

As três diferentes relações treonina digestível: lisina digestível não influenciam de forma significativa o desempenho das aves. Assim, a recomendação proposta para pintos de corte machos no período de oito a 21 dias de idade é a relação de 55,0\% treonina digestível: lisina digestível $(0,631 \%$ de treonina digestível), suplementada com $0,4 \%$ de glicina.

\section{REFERÊNCIAS}

AYASAN, T.; OKAN, F.; HIZLI, H. Threonine requirement of broiler drom 22-42 days. International Journal of Poultry Science, v.8, n.9, p.862-865, 2009. 
Rev. Bras. Saúde Prod. Anim., Salvador, v.13, n.1, p.173-180 jan/mar, 2012 http://www.rbspa.ufba.br ISSN 15199940

CORZO, A.; KIDD, M.T.;

BURNHAM, D.J.; KER, B.J. Dietary glycine needs of broiler chicks. Poultry

Science, v.83, n.8, p. 1382-1384, 2004.

COSTA, F.G.P.; ROSTAGNO, H.S.; ALBINO, L.F.T. Níveis dietéticos de proteína bruta para frangos de corte de 1 a 21 e 22 a 42 dias de idade. Revista Brasileira de Zootecnia, v.30, n.5, p.1498-1505, 2001.

DAVIS, A.T.; AUSTIC, R.E. Threonine metabolism of chicks fed threonineimbalanced diets. The Journal of Nutrition, v.112, n.11, p. 2177-2186, 1982.

DIONÍZIO, M.A. Dietas vegetais com diferentes níveis de proteína e de relação treonina/lisina para frangos de corte. Revista Brasileira de Ciência Avícola, v.5, p.69, 2003.

DOZIER, W.A.; MORAN, E.T.; KIDD, M.T. Broiler chick utilization of threonine from fermentation by-product broth. Journal Applied Poultry Research, v.12, n.3, p.299-305, 2003.

JIANG, Q.; WALDROUP, P.W.; FRITTS, C.A. Improving the Utilization of Diets Low in Crude Protein for Broiler Chicken 1. Evaluation of Special Amino Acid Supplementation to Diets Low in Crude Protein. International Journal of Poultry Science, v.4, n.3, p. 115-122, 2005.
KIDD, M.T.; KERR, B.J. L-threonine for poultry: a review. Journal Applied Poultry Research, v.5, n.4, p.358-367, 1996.

ROSTAGNO, H.S.; ALBINO, L.F.T.; DONZELES, J.L.; GOMES, P.C.; OLIVEIRA, R.F.; LOPES, D.C.; FERREIRA, A.S.; BARRETO, S.L.T. Tabelas Brasileiras para Aves e Suínos: composição de alimentos e exigências nutricionais. Viçosa, MG: Universidade Federal de Viçosa, 2005. $87 \mathrm{p}$.

VASCONCELLOS, C.H.F.; FONTES, D.O.; SILVA, M.A.; CORRÊA, G.S.S.; LARA, L.J.C.; VIDAL, T.Z.B.; MACHADO, A.L.C.; FERNANDES, I.S. Teores de glicina + serina total em dietas de baixa proteína bruta para frangos de corte de 22 a 35 dias de idade. Arquivos Brasileiros de Medicina Veterinária e Zootecnia, v.63, n.3, p.641-648, 2011.

UNIVERSIDADE FEDERAL DE VIÇOSA - UFV. SAEG - Sistema de Análises Estatísticas e Genéticas. Versão 8.0. Viçosa, MG, 2000. 59p.

WALDROUP, P.W.; JIANG, Q.; FRITTS, C. A. Effects of Glycine and Threonine Supplementation on Performance of Broiler Chicks Fed Diets Low in Crude Protein. International Journal of Poultry Science, v.4, n.5, p.250-257, 2005.

Data de recebimento: 29/06/2011

Data de aprovação: 09/12/2011 